\title{
KAJIAN KEBUTUHAN ENERGI SPESIFIK DAN KAPASITAS KERJA MESIN PENGERING GABAH BERBAHAN BAKAR KAYU (STUDI KASUS DI KELOMPOK TANI WARGI MEKAR, DESA TEGAL, KECAMATAN KARAWANG TIMUR, KABUPATEN KARAWANG, PROVINSI JAWA BARAT)
}

\author{
STUDY OF SPECIFIC ENERGY CONSUMPTION AND WORKING CAPACITY \\ OF WOODEN FUEL DRYER (CASE STUDY AT WARGI MEKAR FARMER \\ GROUP, TEGAL VILLAGE, EAST KARAWANG DISTRICT, KARAWANG \\ REGENCY, WEST JAVA PROVINCE)
}

\author{
Wahyu K Sugandi ${ }^{1 凶}$, Boy Macklin $\mathrm{P}^{1}$, Ahmad Thoriq $^{1}$, Fikrialdis Rifki ${ }^{1}$ \\ ${ }^{1}$ Departemen Teknik Pertanian dan Biosistem, Fakultas Teknologi Industri Pertanian, Universitas Padjadjaran \\ $\triangle$ Komunikasi Penulis, email: sugandiwahyu@gmail.com \\ DOI:http://dx.doi.org/10.23960/jtep-l.v10i1.16-25
}

Naskah ini diterima pada 26 Agustus 2020; revisi pada 19 Desember 2020; disetujui untuk dipublikasikan pada 26 Januari 2021

\begin{abstract}
Grain (Oryza sativa L) drying process is generally still done traditionally by direct sunlight. The drying process has several disadvantages such as it can only be done when sunlight is available, a longer drying time, a large area, requirement. An alternative that could be done to dry the grain in addition to using traditional drying was to use a grain dryer machines with do Wargi Mekar Farmer at Kerawang. There are several fuels that are used as heat sources for rice drying machines, one of them is firewood. This study aimed to measure the actual capacity of the wood-fired grain dryer, and also to analyzed the efficiency of drying and specific energy consumption to dry the grain. The research method used is descriptive analysis research method, namely data collection, data processing and data analysis. Research resulted that grain drying using a grain dryer as much as $761 \mathrm{~kg} . \mathrm{hr}^{-1}$. The yield of dry grain is $89.77 \%$, and the value of weight loss is $10.33 \%$. The moisture content of the material after drying is $13.06 \%$ wet basis. The drying efficiency in the process was $17.19 \%$ and the specific energy consumption was 15,318.24 KJ / Kg water vapor.
\end{abstract}

Keywords: efficiency energy, grain drying, specific energy consumption

\begin{abstract}
ABSTRAK
Proses pengeringan gabah (Oryza sativa L) umumnya masih dilakukan secara tradisional dengan cara dijemur di bawah sinar matahari secara langsung. Proses pengeringan tersebut memiliki beberapa kekurangan diantaranya, hanya dapat dilakukan ketika ada sinar matahari, waktu pengeringan yang lama, memerlukan lahan yang luas. Alternatif yang dapat dilakukan untuk mengeringkan gabah selain menggunakan pengeringan secara tradisional adalah menggunakan mesin pengering gabah seperti yang telah dilakukan pada kelompok tani Wargi Mekar, Kabupaten Kerawang namun belum ada kajian berkenaan dengan perhitungan kapasitas kerja mesin pengering dan Kajian kebutuhan energi spesifik mengingat sumber panas dari mesin pengering gabah ini menggunakan bahan bakar yang berasal dari kayu bakar. Penelitian ini bertujuan untuk melakukan pengukuran kapasitas aktual pada mesin pengering gabah berbahan bakar kayu, serta melakuka $\mathrm{n}$ analisis efisiensi pengeringan dan konsumsi energi spesifik untuk mengeringkan gabah. Metode penelitian yang digunakan adalah meteode penelitian analisis deskriptif yaitu pengumpulan data, pengolahan data dan analisis data. Hasil penelitan menunjukkan bahwa pengeringan gabah menggunakan mesin pengering gabah mempunyai kapasitas $761 \mathrm{~kg} / \mathrm{jam}$, Nilai rendemen gabah kering sebesar 89,77\%, dan nilai dari susut bobotnya adalah 10,33\%. Kadar air bahan setelah pengeringan adalah $13,06 \%$ basis basah (bb). Efisiensi pengeringan adalah sebesar 17,19\% dan konsumsi energi spesifiknya adalah sebesar 15.318,24 KJ/Kg uap air.
\end{abstract}

Kata Kunci: Pengeringan gabah, konsumsi energi spesifik, efesiensi energy 


\section{PENDAHULUAN}

Produksi Gabah di Indonesia dari Januari hingga September 2018 sebesar 49,65 juta ton Gabah Kering Giling (GKG). Produksi tertinggi terjadi pada bulan Maret yaitu sebesar 9,46 juta ton, sementara produksi terendah pada bulan Januari yaitu sebesar 2,71 juta ton. Sementara itu, potensi produksi gabah pada bulan Oktober, November, dan Desember masing-masing sebesar 2,66 juta ton, 2,10 juta ton, dan 2,13 juta ton. (BPS, 2108). Perhatian terhadap masalah pascapanen gabah pada saat ini berkembang pesat. Salah satu kegiatan penting pada aktivitas produksi beras adalah pengeringan. Pengeringan merupakan salah satu proses pengeluaran air dari dalam bahan secara termal untuk menghasilkan produk kering. Hasil pertanian setelah dipanen merupakan bahan biologis yang masih memiliki kandungan air yang tinggi. Proses pengeringan gabah umumnya masih dilakukan secara manual dengan metode dijemur di bawah terik sinar matahari langsung, dengan cara dihamparkan setipis mungkin pada lantai jemur. Menurut Graciafernandy dkk., (2012) pengeringan secara manual memiliki beberapa kekurangan seperti terlalu bergantung pada sinar matahari, membutuhkan lahan yang luas, kualitas produk yang tidak seragam, mudah terkontaminasi benda asing, serta waktu pengeringan yang lama. Secara umum, dibutuhkan waktu selama 3 hari untuk mengeringkan gabah bila cuaca cerah, apabila cuaca mendung maka dibutuhkan waktu yang lebih lama.

Permasalahan pada penjemuran gabah tersebut dapat diatasi dengan menggunakan mesin pengering gabah. Kelompok Tani Wargi Mekar merupakan salah satu kelompok tani yang telah menggunakan mesin pengering berada di Kecamatan Karawang Timur, Kabupaten Karawang, Provinsi Jawa Barat. Mesin pengering yang digunakan untuk mengeringkan gabah merupakan mesin pengering tipe bak dengan bahan bakar kayu (Gambar 1). Namun penggunaan alat pengering tersebut di Indonesia masih sedikit karena selain pembuatannya cukup mahal, para petani juga harus menyiapkan dana untuk kebutuhan bahan bakar alat pengering gabah.

Berdasarkan hasil wawancara, kelompok tani belum mengetahui kapasitas kerja mesin pengering gabah dan konsumsi energi spesifik yang digunakan selama proses pengeringan gabah. Kapasitas kerja mesin perlu diketahui untuk dapat dihitung berapa banyak gabah yang dapat dikeringkan untuk satu kali proses pengeringan, sedangkan konsumsi energi spesifik dan efisiensi pengeringan perlu diketahui karena akan sangat berpengaruh terhadap jumlah bahan bakar yang diperlukan ketika melakukan proses pengeringan.

Oleh sebab itu diperlukan suatu penelitian berkenaan dengan pengukuran kapasitas aktual pada mesin pengering gabah berbahan bakar kayu, serta melakukan analisis efisiensi pengeringan dan konsumsi energi spesifik untuk mengeringkan gabah, sehingga dapat diketahui kinerja mesin secara umum.

\section{BAHAN DAN METODE}

Penelitian ini dilaksanakan di Kelompok Tani Wargi Mekar, Desa Tegal di Kecamatan

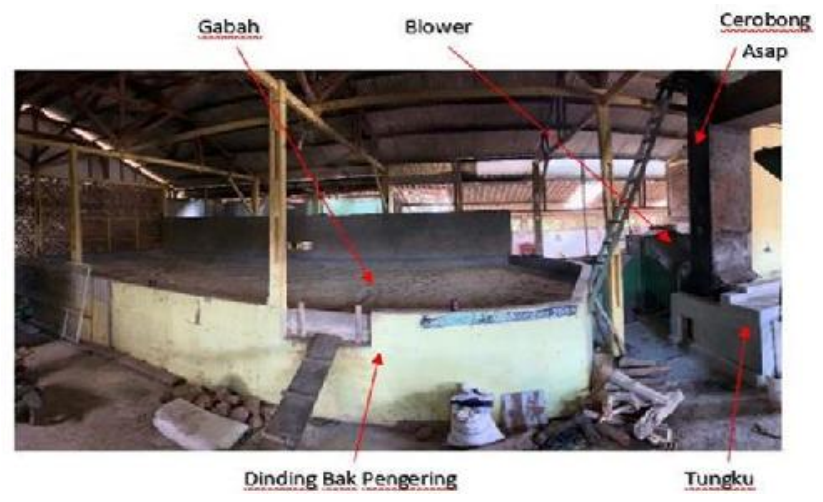

Gambar 1. Mesin Pengering Tipe Bak 
Karawang Timur, Kabupaten Karawang, Jawa Barat. Untuk pengukuran sampel gabah dillakukan di Lab. Pasca Panen Unpad dan Lab. Kimia Fisik ITB. Metode yang digunakan pada penelitian ini adalah analisis deskriptif yaitu pengumpulan data, pengolahan data dan analisis data. Adapun tahapan penelitian seperti yang terlihat pada Gambar 2.

Untuk mengetahui masalah yang ada di kelompok tani Wargi Mekar berkenaan kinerja mesin pengering gabah perlu adanya kunjungan lapang dan memetakkan masalah serta solusi yang tepat untuk memecahkan tersebut. Jenis data yang terbagi menjadi dua yaitu data primer dan data sekunder. Data primer yang didapatkan melalui pengukuran langsung adalah pengambilan sampel gabah yang diukur menggunakan sebuah kotak dari kardus dengan ukuran panjang, lebar dan tinggi adalah 21, 20, $21 \mathrm{~cm}$. Seperti disajikan pada Gambar 3.
Hal ini untuk mengetahui jumlah gabah yang dikeringkan, pada bak pengering melalui perbandingan volume. Adapun cara pengukuran titik suhu pada bak pengering dilakukan sebanyak 9 titik per 15 menit. Seperti disajikan pada Gambar 4.

Selanjutnya data yang diukur adalah suhu uap panas pengering sebanyak 3 titik dan diambil setiap 10 menit. Tujuannya ialah untuk mengetahui berapa suhu uap panas yang dihembuskan pada bak pengeringan tersebut. Pengukuran dilakukan sebanyak 4 kali pengulangan.

Data primer lainnya didapatkan dari hasil uji laboratorium, yaitu data nilai kalor kayu bakar yang digunakan untuk proses pengeringan dengan menggunakan alat bom kalorimeter, jenis kayu yang digunakan maple dengan nilai kadar air gabah basis basah awal adalah $19,6{ }^{\circ} \mathrm{C}$ selama

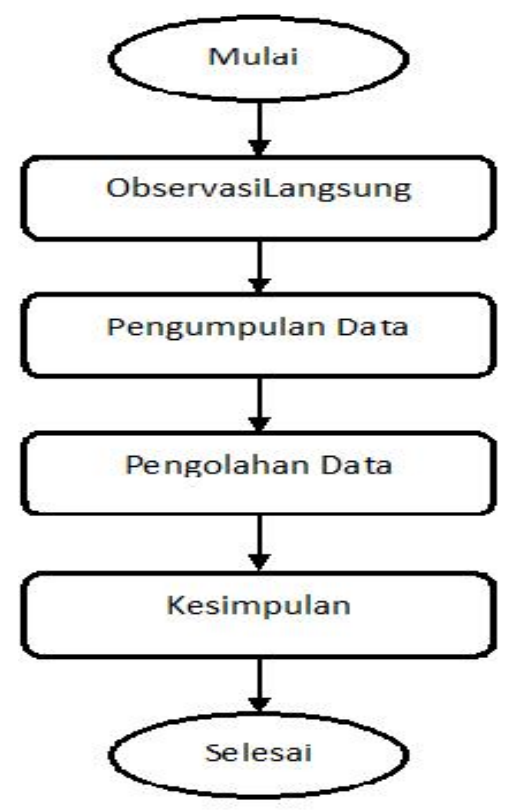

Gambar 2. Tahapan Penelitian

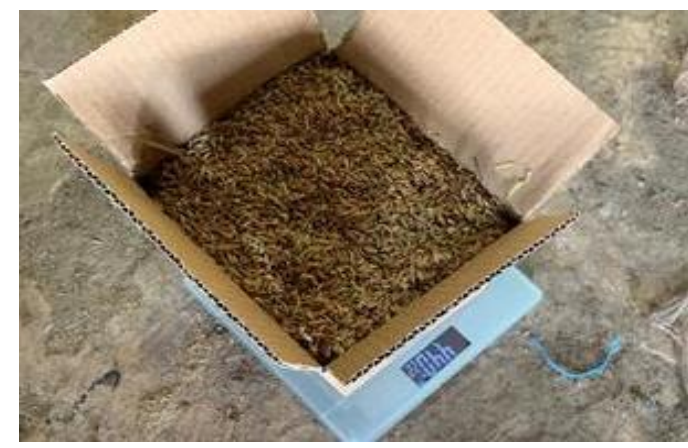

Gambar 3. Dus Kotak Berisi Sampel Gabah 


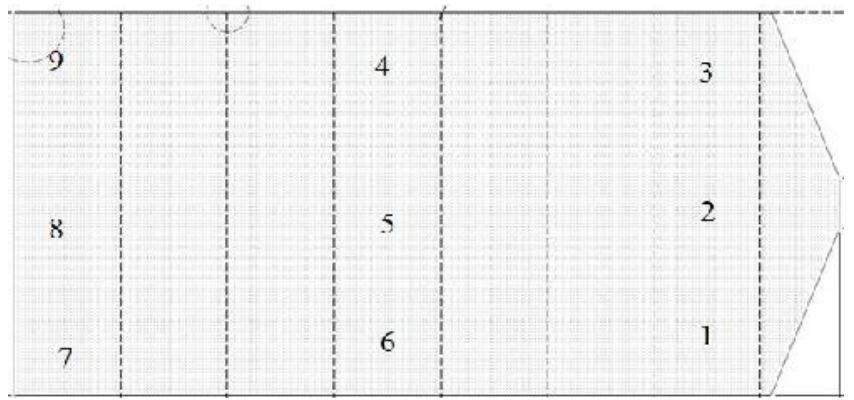

Gambar 4. Penentuan Titik Pengukuran Suhu Lay Out pada Bak Pengering Gabah Tampak Atas

proses pengeringan. Untuk data sekunder diperoleh dari hasil perhitungan dari beberapa persamaan berkenaan kadar air, pengeringan dan energi yang dibutuhkan untuk proses pengeringan yang nantinya akan dianalisis. Adapun beberapa data sekunder yang dihitung adalah sebagai berikut:

\section{Kapasitas maksimum mesin pengering}

Kapasitas maksimum mesin pengering gabah adalah berapa jumlah maksimum massa gabah yang dapat ditampung oleh mesin pengering gabah. Gabah yang dikeringkan di dalam bak pengeringan ditumpuk pada ketinggian $10 \mathrm{~cm}$ secara merata ke seluruh permukaan bak pengeringan. Pengeringan dilakukan pada ketinggian tumpukan gabah $10 \mathrm{~cm}$ dikarenakan untuk menjaga mutu gabah. Apabila pengeringan dilakukan pada ketinggian tumpukan gabah yang terlalu tebal atau lebih dari $10 \mathrm{~cm}$, kemungkinan pengeringan gabah tidak akan terjadi secara merata, terutama pada bagian tengah, sedangkan apabila terlalu tipis, akan terlalu memakan banyak ruang, sehingga volume gabah yang dimasukkan menjadi lebih sedikit dari yang seharusnya.

\section{Laju pengeringan}

Laju pengeringan adalah jumlah penurunan kadar air per satuan waktu. Ditentukan dengan kadar air awal dikurangin kadair air akhir dibagi persatuan waktu ketika pengeringan berlangsung. Hal ini dapat dihitung menggunakan rumus Persamaan 1 (Pangabean,2016):

$$
L P=\frac{K_{0-} K_{1}}{t}
$$

Dengan, LP merupakan laju pengeringan kadar air (\%bb/menit), Ko adalah kadar air awal (\%bb), $\mathrm{K}_{1}$ adalah kadar air akhir (\%bb), dan tadalah waktu pengeringan (menit).

\section{Rendemen dan bobot gabah}

Rendemen adalah jumlah persentase dari berat gabah sebelum pengeringan dibagi berat gabah setelah pengeringan. Gabah siap giling haruslah memenuhi persyaratan-persyaratan rendemen dapat dihitung dengan Persamaan 2 dan bobot dihitung dengan Persamaan 3 (Thoriq, 2019).

$$
\begin{aligned}
R_{p} & =\frac{m f}{m o} \times 100 \% \\
B_{p} & =\frac{m o-m f}{m o} \times 100 \%
\end{aligned}
$$

Dimana, $R_{p}$ adalah rendemen gabah (\%), $B_{p}$ adalah susut bobot gabah (kg), mf adalah bobot setelah pengeringan $(\mathrm{kg})$, dan mo adalah bobot awal sebelum pengeringan $(\mathrm{kg})$.

\section{Kadar air bahan}

Salah satu faktor yang mempengaruhi pengeringan adalah kadar air bahan. Pengeringan bertujuan untuk mengurangi kadar air bahan sehingga menghambat perkembangan organisme pembusuk. Kadar air suatu bahan berpengaruh terhadap banyaknya air yang diuapkan dan lamanya proses pengeringan (AOAC, 1999). Dalam penentuan kadar air bahan biasanya dinyatakan berdasarkan kadar air basis kering (dry basis), dan kadar air basis basah (wet basis). Kadar air bahan basis basah dapat dinyatakan pada Persamaan 4 dan kadar air bahan basis kering dapat pada Persamaan 5 .

$$
\begin{aligned}
& M(b b)=\frac{A-(C-A)}{B} \times 100 \% \\
& M(b k)=\frac{B-(C-A)}{(C-A)} \times 100 \%
\end{aligned}
$$

Dimana A merupakan massa cawan, B adalah massa bahan awal, dan $\mathrm{C}$ adalah massa bahan + cawan kering. 


\section{Energi untuk memanaskan dan menaikkan suhu bahan}

Perhitungan untuk mengatahui energi memanaskan dan menaikkan suhu bahan gabah bisa dihitung dengan Persamaan 6 (Siebel 1892 dalam Syafarudin 2018):

$$
\begin{aligned}
C_{p p} & =0,837+0,034\left(M^{\prime}\right) \\
Q_{1} & =\operatorname{mo} \times C_{p p} \times\left(\mathrm{Tr}-T_{1}\right)
\end{aligned}
$$

Dimana M' adalah kadar air akhir gabah, $Q_{1}$ adalah energi untuk memanaskan pada bahan (kj), $C_{p F}$ adalah kapasitas panas spesifik gabah pada kadar air $\mathrm{M}^{\prime}\left(\mathrm{kj} / \mathrm{kg}^{\circ} \mathrm{C}\right)$, $\mathrm{Tr}$ adalah suhu ratarata bak pengeringan $\left({ }^{\circ} \mathrm{C}\right)$, dan $T_{1}$ adalah suhu awal pada bak pengeringan $\left({ }^{\circ} \mathrm{C}\right)$.

\section{Energi untuk menguapkan air bahan}

Energi untuk menguapkan air bahan dihitung menggunakan Persamaan 8 sebagai berikut (Thoriq, 2019):

$$
Q 2=\operatorname{mu} x \mathrm{Hfg}
$$

Dengan Q2 adalah energi untuk menguapkan air bahan (kJ), Hfg adalah panas laten penguapan bahan pada suhu rata-rata pengeringan $(\mathrm{kJ} / \mathrm{kg})$ yang diperoleh dari tabel properti termodinamika pada suhu rata-rata ruang Pengeringan, mu adalah berat uap air gabah yaitu (Thoriq, 2019):

$$
m u=\frac{\mathrm{m} 0 \mathrm{x}(\mathrm{ka} 1-\mathrm{ka} 2)}{(100-\mathrm{ka} 2)}
$$

Dimana mu adalah bobot uap air pad gabah (kg), ka1 adalah kadar air awal (\%bb), dan ka2 adalah kadar air akhir (\%bb).

\section{Kebutuhan energi pada proses pengeringan gabah}

Kebutuhan energi untuk pengeringan pada gabah dapat diketahui dengan cara penjumlahan dari energi untuk memanaskan bahan dan energi untuk menguapkan air bahan, Persamaan 10 pada kebutuhan energi:

$$
Q_{3}=Q_{1}+Q_{2}
$$

\section{Energi pada pembakaran kayu}

Bahan bakar kayu ini sumber utama dalam proses pengeringan gabah dengan mesin pengering gabah berbahan bakar kayu dan dapat dihitung energinya dengan Persamaan 11 (Panggabean,2016):

$$
Q_{k y}=m_{k y} \times N_{k y}
$$

Dengan, $Q_{k y}$ adalah energi pembakaran kayu (kj), $m_{k y}$, adalah massa kayu yang terpakai $(\mathrm{kg})$, dan $N_{k y}$ Nilai kalor kayu $(\mathrm{kj} / \mathrm{kg})$.

\section{Efesiensi pengeringan}

Efisiensi pengeringan adalah presentase tingkat kegunaan pada proses pengeringan gabah dan dapat dihitung dengan Persamaan 12 (Thoriq, 2019). Konsumsi Energi Spesifik (KES) dihitung denganPersamaan 13.

$$
\begin{aligned}
\eta \mathrm{t} & =\frac{Q 1+Q 2}{Q_{k y}} \times 100 \% \\
K E S & =\frac{Q k y}{m u}
\end{aligned}
$$

Dimana, Q1 adalah unit energi untuk memanaskan bahan, Q2 adalah unit energi untuk menguapkan air bahan, $Q_{k y}$ adalah unit energi pada pembakaran kayu (kj).

\section{HASIL DAN PEMBAHASAN}

\subsection{Kapasitas Mesin Pengering}

Jumlah maksimum gabah yang dapat dimasukkan pada bak pengeringan dihitung dengan menggunakan perhitungan kapasitas gabah. Kapasitas gabah dihitung dengan membandingkan massa gabah sampel pada wadah berupa kotak dengan volume sebesar $0,00882 \mathrm{~m}^{3}$. (Gambar 3). Pengujian sebanyak 4 kali pengukuran, massa sampel gabah pada volume kotak tersebut (gabah memenuhi kotak) sebelum dilakukan pengeringan rata-rata adalah 4,4 kg. Setelah dilakukan pengeringan, massa gabah dalam kotak menjadi rata-rata 3,95 kg. Adapun kapasitas mesin pengering gabah berdasarkan perbandingan bahan dapat dilihat pada Tabel 1.

Diketahui bahwa massa gabah apabila bak diisi gabah dengan tinggi tumpukan $10 \mathrm{~cm}$ (Gambar 5) sebelum pengeringan (waktu 0 menit) ratarata adalah $3293 \mathrm{~kg}$, sedangkan massa gabah setelah pengeringan dengan lama waktu pengeringan 4 jam rata-ratanya adalah $3044 \mathrm{~kg}$. 
Tabel 1. Kapasitas Mesin Pengering Rata-rata Berdasarkan Perhitungan dengan Tinggi Tumpukan Gabah $10 \mathrm{~cm}$

\begin{tabular}{lcc}
\hline \multicolumn{1}{c}{ Kapasitas } & Sebelum Pengeringan & Sesudah Pengeringan \\
\hline Volume Kotak $\left(\mathrm{m}^{3}\right)$ & 0,0088 & 0,0088 \\
Berat Sampel gabah dalam kotak $(\mathrm{kg})$ & 4,40 & 3,95 \\
Volume bak pengering $\left(\mathrm{m}^{3}\right)$ & 6,60 & 6,60 \\
Berat gabah dalam bak pengering $(\mathrm{kg})$ & 3292,58 & 3044,12 \\
\hline
\end{tabular}

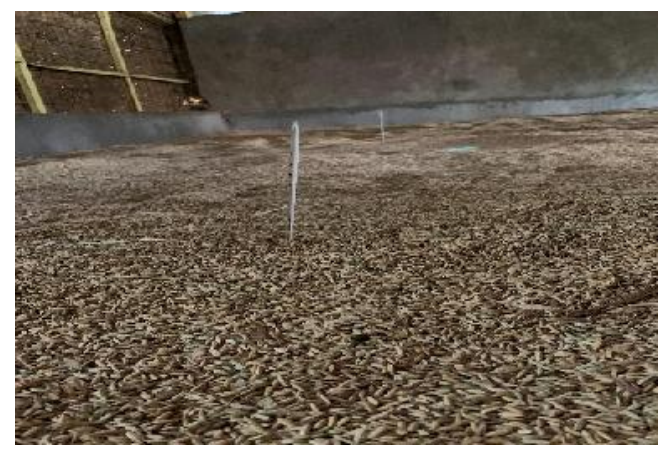

Gambar 5. Bak Pengering Gabah

sehingga kaspasitas mesin pengering setelah dikeringkan adalah $761 \mathrm{~kg} / \mathrm{jam}$.

\subsection{Rendemen Pengering}

Nilai rendemen gabah kering berdasarkan Persamaan 2 adalah 89,77\%. Hal tersebut ditunjang oleh Survey Konversi Gabah ke Beras (SKGB ,2018) konversi nilai Gabah Kering Panen (GKP) ke Gabah Kering Giling (GKG) hasil proses pengeringan gabah di Wilayah Jawa Barat adalah 81,99\%. Oleh karena itu, secara rendemen mesin ini layak untuk digunakan dan nilai rendemen tersebut mendekati nilai proses pengeringan gabah yang ada di Jawa Barat.

\subsection{Kadar Air Gabah}

Berdasarkan hasil pengukuran dan perhitungan pada Persamaan 5 dan 6) diketahui bahwa kadar air bahan sebelum pengeringan adalah 19,60\% basis basah (bb) sedangkan kadar air bahan setelah pengeringan adalah $13,06 \%$ basis basah (bb). Nilai tersebut didapatkan dari uji laboratorium terhadap sampel yang diambil dari hasil pengeringan.

\subsection{Laju Pengeringan}

Berdasarkan hasil pengukuran pada persamaan 2, diketahui bahwa laju pengeringan gabah selama adalah $0,027 \% / m e n i t$. Nilai laju pengeringan tersebut selain dipengaruhi oleh kadar air awal gabah, juga dipengaruhi oleh suhu dan jenis perpindahan panas yang terjadi.
Semakin tinggi suhu pengeringan, maka akan semakin tinggi nilai laju pengeringan yang terjadi. Namun peningkatan suhu tidak dilakukan dikarenakan suhu di atas $60^{\circ} \mathrm{C}$ dikhawatirkan dapat merusak gabah.

\subsection{Profil Suhu Selama Proses Pengeringan Gabah}

Pengeringan gabah dengan mesin pengering gabah tipe bak pada penelitian ini membutuhkan waktu 4 jam dimana kadar air awal gabah 19,6 \%bb dikeringkan hingga kadar air mencapai 13,06 \%bb. Penelitian gabah dilakukan dengan suhu rata-rata bak pengering sekitar $49,57^{\circ} \mathrm{C}$, serta suhu bahan gabah rata-rata $44,26^{\circ} \mathrm{C}$ (dengan alat ukut menggunakan thermometer air raksa).

Sebelum gabah dimasukkan saat pengeringan, tungku dipanaskan dan blower dinyalakan selama 5 menit. Hal tersebut dilakukan selain untuk melakukan pemanasan pada bak pengering, juga untuk memastikan udara sebagai penghantar panas sudah berhembus secara optimal. Keadaan bak pengering sebelum dilakukan pengeringan memiliki kelembaban udara rata-rata sekitar 50,33\% (dengan menggunakan alat ukur RH Meter) Hal tersebut menyebabkan sebelum menaikan suhu bak pengering sesuai yang diinginkan, dilakukan terlebih dahulu pemanasan untuk mengurangi kelembaban udara dalam bak pengering. 
Profil suhu bak pengering serta profil suhu bahan saat pengeringan dapat dilihat pada Gambar 6 dan 7. Ketika gabah dimasukkan, suhu bak pengering sekitar $28,33^{\circ} \mathrm{C}$. Pengeringan mula-mula akan mengeluarkan energi untuk melakukan pemanasan terhadap gabah, setelah melakukan pemanasan, dapat dilakukan penguapan kadar air bahan, sehingga kadar air bahan akan berkurang sampai pada titik kesetimbangan.

Profil suhu bahan dapat dilihat pada Gambar 6, pada titik 8 suhu pengeringan yang paling tinggi dan waktu kenaikkan suhu pada menit ke 15. Hal ini disebabkan uap panas pada yang disaluran terlebih dahulu ke titik 8 dan setelah itu uap panas terjebak dan berbalik lagi ke titik 2. Pada menit ke 120 hingga menit 165 terjadi penurunan yang signifikan dikarenakan bahan bakar kayu sudah mulai berkurang. Proses akhir pembakaran mengalami penurunan suhu pada menit ke $180^{\circ} \mathrm{C}$ dikarenakan jumlah kayu bakar yang ada di dalam tungku sudah mulai habis. Karena bahan bakar kayu menggunakan sistem batch, bila kayu bakar di ruang bakan habis maka bahan bakar kayu diisi ulang.

Pada Gambar 6 juga menunjukkan pengeringan bahan gabah yang dilakukan dalam bak pengering tidak memiliki nilai suhu bahan yang seragam. Ada beberapa hal yang menjadi alasan nilai suhu tersebut memiliki nilai yang berbeda. Pertama, suhu pengeringan pada mesin berasal dari pembakaran kayu bakar. Proses pengeringan yang menggunakan pembakaran kayu bakar memiliki kekurangan api hasil pembakarannya sulit untuk dikendalikan, sehingga sulit pula untuk membuat suhu pengeringan menjadi seragam ditiap pengukuran. Kedua, selain bergantung pada suhu, pengeringan juga bergantung pada keseragaman aliran udara yang dihasilkan oleh blower. Apabila aliran udara tidak seragam di tiap pengukuran, maka proses perpindahan panas konveksi tidak terjadi secara merata.

Gambar 7 menunjukan profil suhu bak pengering yang diukur pada 3 titik bak pengering, di mana ketiga titik tersebut berada di dekat blower, ruang pemasukan udara ke bak pengering, serta di ujung bak pengering. Nilai suhu bak pengering tertinggi ketika kondisi tersebut adalah sekitar $57^{\circ} \mathrm{C}$ pada menit ke 120 , dengan nilai rata-rata sebesar $49,57^{\circ} \mathrm{C}$. Pengeringan masih berada dalam suhu ideal pengeringan bahan pertanian. Hal tersebut ditunjang oleh Indriani dkk. (2009) yang menyatakan bahwa pengeringan bahan hasil pertanian dengan menggunakan aliran udara pengering yang baik adalah antara $45^{\circ} \mathrm{C}$ $75^{\circ} \mathrm{C}$. Pengeringan pada suhu di bawah $45^{\circ} \mathrm{C}$, mikroba dan jamur masih hidup, sehingga daya awet dan mutu produk rendah. Namun, suhu udara pengering di atas $75^{\circ} \mathrm{C}$ menyebabkan struktur kimiawi dan fisik produk rusak.

Berkenaan sistem pemasukkan bahan bakar kayu menggunakan sistem batch, ppengukuran Profil suhu pada bak pengering hanya dilakukan selama 120 menit Hal tersebut dikarenakan pada menit ke 120, kayu bakar pada tungku pembakaran telah menjadi arang, sehingga diperkirakan bahwa suhu yang dihasilkan sudah

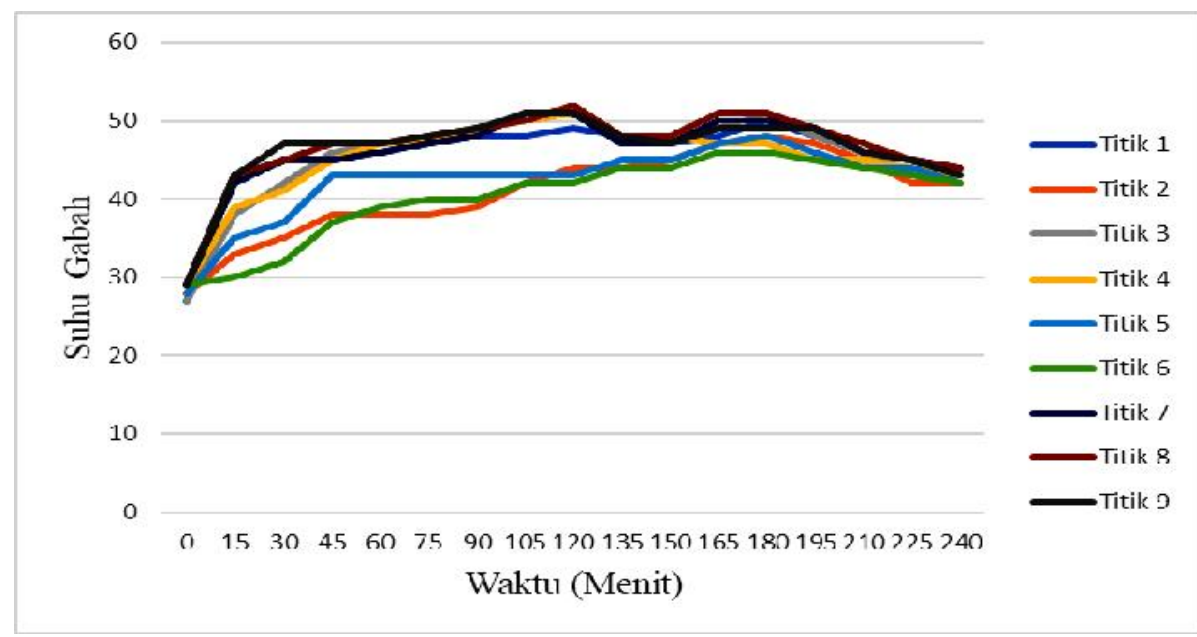

Gambar 6. Profil Suhu Bahan Gabah Selama Proses Pengeringan 


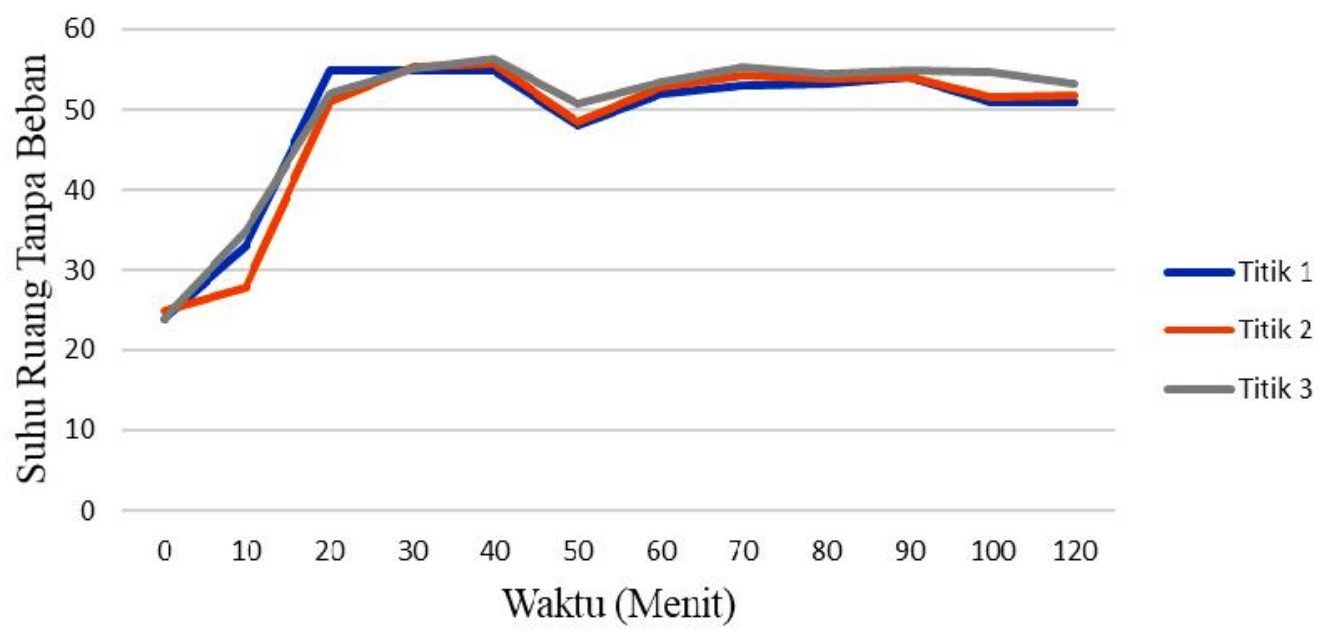

Gambar 7. Profil Suhu Bak Pengeringan

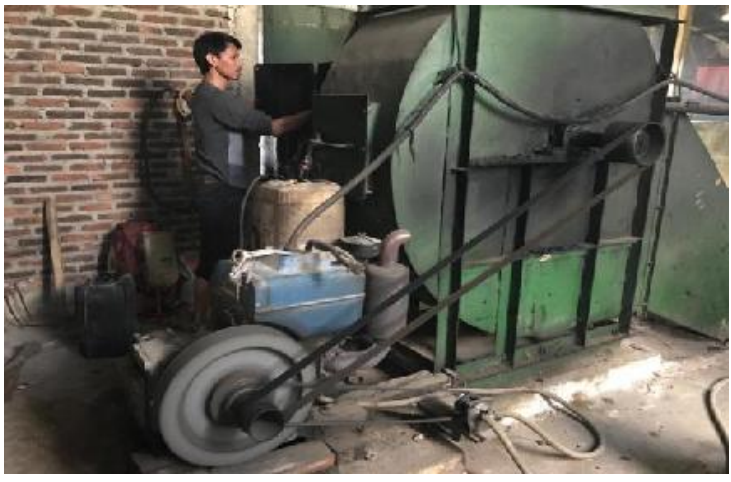

Gambar 8. Blower Pengantar Uap Panas

mencapai titik optimum. Setelah itu maka akan dimasukkan kembali kayu bakar kedalam tungku pembakaran. Adapun profil suhu bak pengeringan seperti disajikan pada Gambar 7 .

\subsection{Konsumsi Bahan Bakar Selama Proses Pengeringan}

Bahan bakar kayu dan solar yang siapkan untuk proses pengeringan ini adalah sebanyak $216 \mathrm{~kg}$ dan 19 liter. Solar disini digunakan untuk menggerakkan blower (Gambar 8) sebagai pengantar uap panas ke dalam bak pengeringan. Dari hasil pengukuran bahan bakar kayu dan solar yang digunakan sebesar $127 \mathrm{~kg}$ dan 9,9 liter sehingga konsumsi bahan bakar kayu dan solar sebesar 31,7 kg/jam dan 2,4 liter/jam.

\subsection{Efisiensi Mesin Pengering}

Selama proses pengeringan dibutuhkan energi untuk memanaskan dan menaikkan suhu pada gabah yang dikeringkan sesuai Persaman 8 adalah sebesar 58.814,95 kJ, sedangkan energi yang dibutuhkan untuk menguapkan air pada bahan gabah sesuai persamaaan 9) adalah sebesar 591.756,4 kJ kebutuhan energi dalam satu kali proses pengeringan gabah sesuai persamaan 11) adalah sebesar sebesar $650.580,35 \mathrm{~kJ}$. Berdasarkan data tersebut, didapatkan nilai konsumsi energi spesifik sesuai persamaan 14) sebesar 15.318,24 kj/kg uap air, artinya untuk menguapkan $1 \mathrm{~kg}$ uap air dibutuhkan energi sebesar 15.318,24 kj. Kebutuhan energi tersebut termasuk cukup besar dikarenakan efisiensi pengeringan susuai persaman 13)yang cukup kecil, yaitu hanya sebesar 17,19\%. Efisiensi pengeringan memiliki nilai yang kecil dikarenakan pada penggunaan kayu bakar sebagai bahan bakar utama pengeringan, tidak $100 \%$ panas dapat digunakan untuk proses pengeringan. Banyak panas yang terbuang ke luar bak pengeringan, ada juga panas yang terbuang melalui ruang cerobong asap saat pengeringan. Salah satu upaya yang dapat dilakukan untuk menaikkan nilai efisiensi 
Tabel 2. Kinerja Proses Pengeringan Mesin Pengering Gabah Berbahan Bakar Kayu

\begin{tabular}{llcc}
\hline No & \multicolumn{1}{c}{ Keterangan } & Hasil Pengukuran/ Perhitungan & Satuan \\
\hline 1 & Berat Awal & 3292,58 & $\mathrm{Kg}$ \\
2 & Berat Akhir & 3044,12 & $\mathrm{Kg}$ \\
3 & Kadar Air Awal & 19,60 & $\% \mathrm{bb}$ \\
4 & Kadar Air Akhir & 13,08 & $\% \mathrm{bb}$ \\
5 & Susut Berat Gabah & 10,23 & $\%$ \\
6 & Rendemen & 89,77 & $\%$ \\
7 & Panas Spesifik Gabah & 0,841 & $\mathrm{kj} / \mathrm{kg}{ }^{\circ} \mathrm{C}$ \\
8 & Energi untuk memanaskan dan & $58.814,95$ & $\mathrm{kj}$ \\
& menaikan suhu bahan & & \\
9 & Berat Uap air gabah & 246,982 & $\mathrm{~kg}$ \\
10 & Panas Laten & $2.395,95$ & $\mathrm{kj} / \mathrm{kg}$ \\
11 & Energi untuk Menguapkan Air & $591.756,40$ & $\mathrm{Kj}$ \\
& Bahan & & \\
12 & Kebutuhan Energi & $650.580,35$ & $\mathrm{Kj}$ \\
13 & Konsumsi Solar & 2,40 & $\mathrm{Liter} / \mathrm{jam}$ \\
14 & Konsumsi Kayu & 31,70 & $\mathrm{Kg} / \mathrm{jam}$ \\
15 & Nilai Kalor Kayu & 29.790 & $\mathrm{kj} / \mathrm{kg}$ \\
16 & Waktu Pengeringan & 240 & $\mathrm{menit}$ \\
17 & Suhu Awal Bak Pengeringan & 28,33 & ${ }^{\circ} \mathrm{C}$ \\
18 & Suhu Rata-rata Bahan & 44,26 & ${ }^{\circ} \mathrm{C}$ \\
19 & Suhu Rata-rata Pengeringan & 49,57 & ${ }^{\circ} \mathrm{C}$ \\
20 & Efisiensi Pengeringan & 17,19 & $\%$ \\
21 & Konsumsi Energi Spesifik & $15.318,24$ & $\mathrm{kj} / \mathrm{kg} \mathrm{uap} \mathrm{air}$ \\
\hline & & &
\end{tabular}

pengeringan adalah dengan cara menambahkan isolator pada bak pengering. Isolator pada bak pengering akan berfungsi untuk meminimalkan terbuangnya panas dalam bak pengering ke lingkungan.

Energi pembakaran kayu bakar sesuai Persamaan 12 sebesar $3.783 .33 \mathrm{kj}$, dimana besarnya nilai kalor yang dihasilkan kayu bakar maple yaitu $7120 \mathrm{kal} / \mathrm{gram}$ atau $29.790 \mathrm{kj} / \mathrm{kg}$. Hal ini didasarkan pada mutu briket arang kayu yang mensyaratkan nilai kalor briket minimum $5000 \mathrm{kal} /$ gram sesuai dengan standar nasional (SNI 01-6235-2000).

\subsection{Kinerja Proses Pengeringan}

Adapun kinerja mesin pengering gabah ketika melakukan proses pengeringan tersebut dapat dilihat pada Tabel 2.

\section{KESIMPULAN}

Kapasitas aktual dari mesin pengering gabah tipe bak yang digunakan adalah $761 \mathrm{~kg} / \mathrm{jam}$. Nilai rendemen gabah kering sebesar $89,77 \%$. Kadar air bahan setelah pengeringan adalah 13,06\% basis basah (bb). Efisiensi pada proses pengeringan gabah dengan menggunakan mesin pengering gabah ini yaitu sebesar 17,19\% dan konsumsi energi spesifik sebesar 15.318,24 kJ/ Kg uap air. Nilai Efisiensi tersebut tidak terlalu besar karena banyak panas yang dibuang ke lingkungan.

\section{DAFTAR PUSTAKA}

AOAC. 1999. Official Methods of Analysis of the Association of Official of Analitycal Chemist. Washington D.C.: AOAC, Inc.

Badan Pusat Statistik. 2018. Tanaman Pangan: Gabah Indonesia. Jakarta.

Graciafernandy, Ratnawati, Buchori. 2012. Pengaruh Suhu Udara Pengering dan Komposisi Zeolit 3a Terhadap Lama Waktu Pengeringan Gabah pada Fluidized Bed Dryer. Momentum 8 (2)Oktober 2012 :6- 10. 
Indriani, I. 2009. Petunjuk Teknis Penanganan Gabah. Jawa Barat : Balai Pengkajian teknologi Pertanian (BPTP).

Pangabean, Triyana, Hayati. 2017. Kinerja Pengeringan Gabah Menggunakan Alat Pengering Tipe Rak dengan Energi Surya, Biomassa, dan Kombinasi. Program Studi Teknik Pertanian, Jurusan Teknologi Pertanian, Universitas Sriwijaya. Jurnal Agritech 37(2) : 229-235.

Syafarudin. 2018. Rangcangan Sistem Pemanasan dan Uji Kinerja pada Pengering Gabah tipe Bak dengan dan
Tanpa Tempering [Skripsi]. Departemen Teknik Mesin dan Biosistem. IPB

SKGB. 2018. Konversi Gabah ke Beras. Katalog BPS. PT Citra Mawana Patamaro.

Standar Nasional Indonesia. 2000. SNI Briket Arang Kayu SNI 01-6235-2000. Badan Standarisasi Nasional.

Thoriq, Widyasanti. 2019. Analisis Kinerja Pemanggang Ubi Cilembu (Ipomoea Batatas L) Menggunakan Oven Berbahan Bakar Liquified Petroleum Gas (LPG). Jurnal Teknik Pertanian Lampung 8 (1) :57-64. 